\title{
ФОТОХИМИЧЕСКОЕ ОКИСЛЕНИЕ ПОЛИЦИКЛИЧЕСКИХ АРОМАТИЧЕСКИХ УГЛЕВОДОРОДОВ В ПРИСУТСТВИИ ИОННЫХ ПОВЕРХНОСТНО-АКТИВНЫХ ВЕЩЕСТВ
}

\author{
(Представил М. Губергриц)
}

В настоящее время все более значительным становится вклад синтетических поверхностно-активных веществ (СПАВ) в. общий объем запрязнений, попадающих в гидросферу. СПАВ относятся к соединениям, деградация которых в окружающей среде протекает малоинтенсивно, поэтому они способны накапливаться в значителыных количествах, увеличивая токсичные или канцерогенные свойства других соединений $\left[{ }^{1,2}\right]$.

Цель настоящего исследования заключается в изучении влияния ионных СПАВ на кинетику превращения полициклических ароматических углеводородов (ПАУ) под воздействием УФ-излучения (естественный фактор среды, обусловливающий их деградацию) в водной среде и в мицеллярных системах, которые представляют собой удобную модель липидных мембран.

\section{Экспериментальная часть}

- Объектами исследования служили следующие модельные ПАУ: антрацен (очищен зонной плавкой), нафталин (очищен сублимацией), пирен («Союзхимреактив»), 7,12-диметилбенз (а) антрацен (ДМБА) («Fluka $A G »)$.

Методика кинетического эксперимента заключалась в облучении светом с длиной волны 313 нм, выделенным из общего спектра излучения ламп ДКсШ-1000 или ДРШ-1000 посредством интерференционного фильтра, водных растворов указанных аренов в присутствии различных количеств СПАВ: синтезированного нами 1-децилбензолсульфоната натрия - napa-изомер (ДБС) [3]; додецилсульфата натрия ДСН («Шостка», ч.), очищенного перекристаллизацией из этанола; бромистого цетилтриметиламмония (БЦТА), многократно перекристаллизованного из смеси ацетона с ацетонитрилом $(3: 1)$. Bсе эксперименты проведены при комнатной температуре и интенсивности облучения $\sim 10^{16}$ квант/мл.c, в стеклянном цилиндрическом реакторе с магнитной мешалкой. Концентрации пирена, ДМБА, антрацена, нафталина были соответственно равны $5 \cdot 10^{-7} ; 2 \cdot 10^{-7} ; 1 \cdot 10^{-6} ; 1,5 \cdot 10^{-4} M$, что не превышало предела их растворимости в воде [ $\left.{ }^{4}\right]$. Величины квантовых выходов рассчитывали по формуле

$$
\varphi=\frac{k \cdot N_{A} \cdot \lg e}{I_{0} \cdot l \cdot \varepsilon},
$$

где $\varphi$ - квантовый выход фотодеградации, мол/кв; $N_{A}$ - число Авогадро; $I_{0}$ - интенсивность падающего света, $\kappa в / м л \cdot м u н$, определяемая 


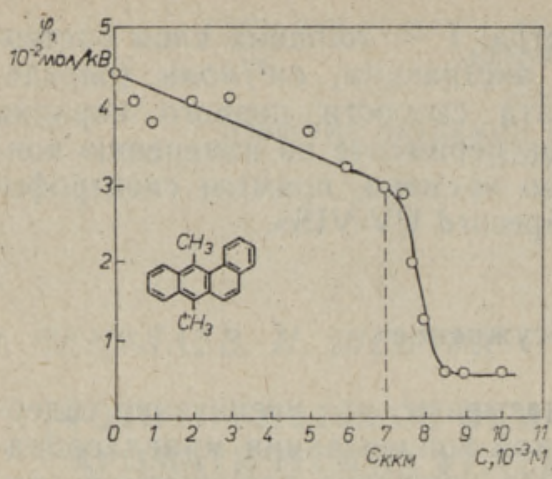

Рнс. 3. Зависимость квантового выхода фотоокисления ДМБА от концентрации ДСН в водном растворе.

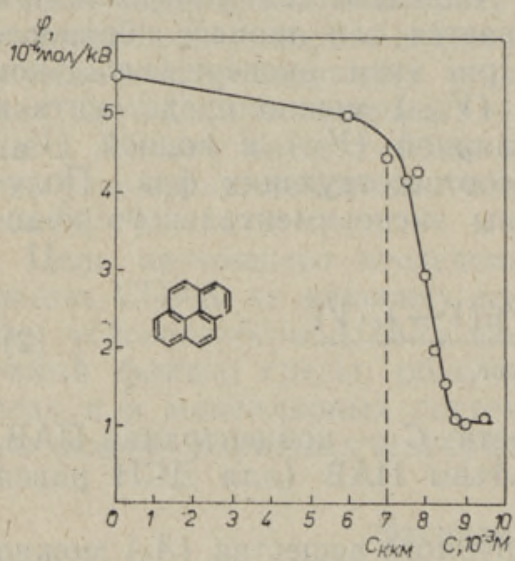

Рис. 5. Зависимость квантового выхода фотоокисления пирена от концентрацни ДСН в водном растворе.

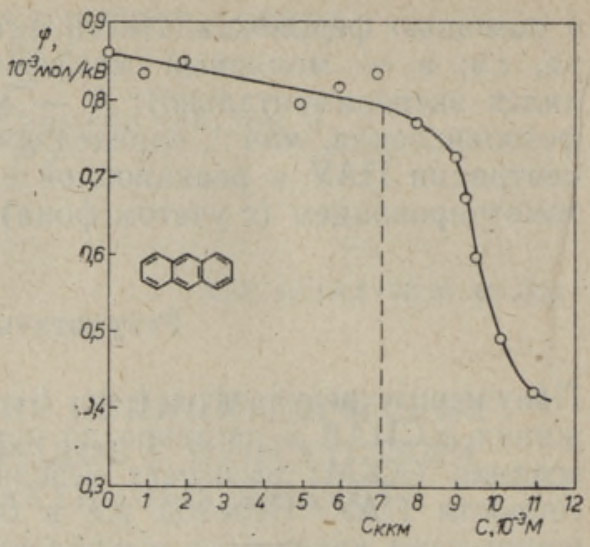

Рис. 4. Зависимость квантового выхода фотоокисления антрацена от концентрации ДСН в водном растворе.

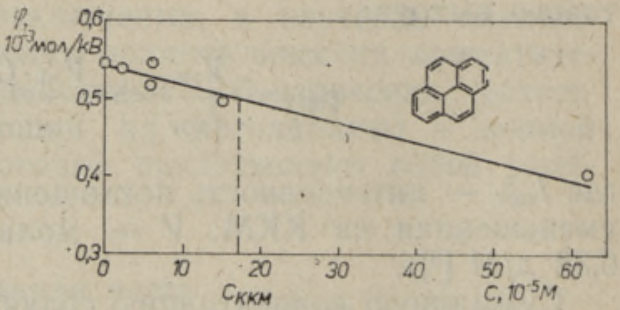

Рис. 6. Зависимость квантового выхода фотоокисления пирена от концентрацин ДБС в водном растворе.

шение концентраций распределенного вещества между мицеллярной и водной фазами (коэффициент распределения) следующее:

$$
P_{A}=\frac{A_{\mathrm{M}}}{A_{\mathrm{B}}} .
$$

Исходя из равенства коэффициентов молярной экстинкции вещества в воде и в мицелле, на основе уравнений (3) и (4), получим:

$$
\varphi_{\text {экс }}=\frac{\varphi_{\mathrm{M}} \cdot P_{A} \cdot C \cdot V+\varphi_{B}(1-C \cdot V)}{1+\left(P_{A}-1\right) C \cdot V},
$$

где $\varphi_{м}$ и $\varphi_{\text {в }}$ - квантовые выходы фотодепрадации в мицелле и в воде. T. к. в данном случае $C \cdot V \ll 1$ и $P_{A} \gg 1$, то при значении $C \cdot V \ll 0,01$ выражение (5) упрощается:

$$
\varphi_{\text {әкс }}=\frac{\varphi_{\mathrm{M}} \cdot P_{A} \cdot C \cdot V+\varphi_{\mathrm{B}}}{1+P_{A} \cdot C \cdot V} .
$$

Оно отвечает известному уравнению Грюнвальда [5], где вместо величин констант скоростей реакций подставлены соответствую́щие значения квантовых выходов. 


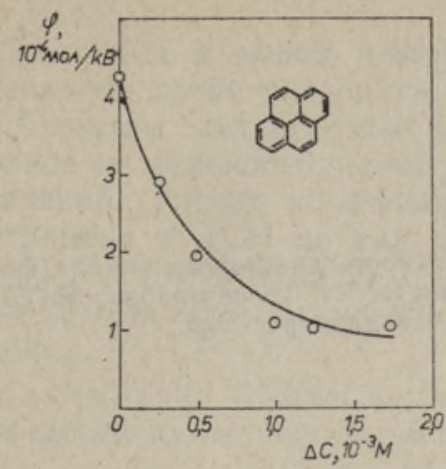

Рис. 7. Влияние ДСН на квантовый выход фотоокисления пирена в водном растворе $\left(\Delta C=C_{\text {дсн }}-C_{\mathrm{KKM}}\right)$. Кривая рассчитана по уравнению (6).

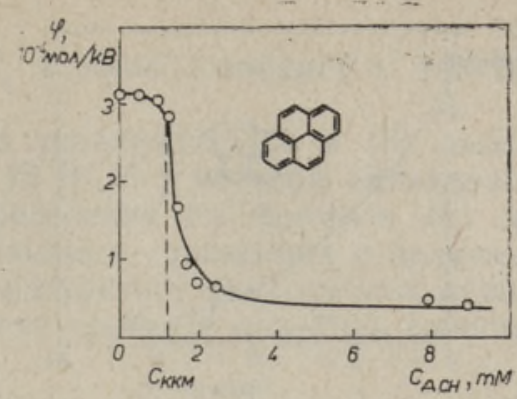

Рис. 8. Завнснмость квантового выхода фотоокисления пирена от концентрации ДСН $0,1 \mathrm{M}$ в водном растворе $\mathrm{NaCl}$.

Нами установлено, что изменение реакционной способности ПАУ в области ККМ (рис. 7) хорошо описывается выражением (6). На основе уравнения (6) и полученных зависимостей үәкс от $C$ рассчитаны значения коэффициентов распределения $\left(P_{A}\right)$ исследованных ПАУ между мицеллярной фазой, создаваемой ДСН, и водой. При этом полученные коэффициенты распределения оказались равными для антрацена $\left(1,8 \cdot 10^{3}\right), 7,12$-ДМБА $\left(6,6 \cdot 10^{3}\right)$ и для пирена $\left(7,2 \cdot 10^{3}\right)$. Следует особо отметить, что мицеллярные эффекты проявляются лишь при условии солюбилизации исследуемого ПАУ. Так, в случае пирена, молекулы которого не солюбилизируются в мицеллах ДБС, наблюдается лишь неболышое падение окорости его фотодеградации (рис. 6). В мицеллах ДСН пирен солюбилизируется и примерно в пять раз уменьшается скорость его фотоокисления (рис. 5). Эти факты позволяют предположить, что наряду с гидрофобным взаимодействием существенное значение в связывании ПАУ с мицеллами $a$-СПАВ приобретает взаимодействие заряженных прупп поверхности мицеллы с $\pi$-электронной системой ароматического ядра. Для проверки этого предположения нами был поставлен эксперимент по фотоокислению пирена в мицеллярном растворе ДСН с добавкой $\mathrm{NaCl}$ в концентрации $0,1 \mathrm{M}$. В этих условиях наблюдается снижение КKM и поверхностного заряда мицеллы, но не изменяются ее геометрические параметры и число агрегаций [6].

Коэффициент распределения пирена между мицеллярной фазой и водой, рассчитанный на основе данных, представленных на рис. 8, оказался равным $15,5 \cdot 10^{3}$. Таким образом, введение противоиона привело к двухкратному увеличению количества солюбилизированного пирена, т. е. в мицеллах $a$-СПАВ в результате полярных взаимодействий процесс солюбилизации ПАУ несколько затруднен. В мицеллах же катионных ПАВ солюбилизация аренов (например, пирена) должна быть облегчена за счет притяжения отрицательно заряженной молекулы пирена к положительно заряженным мицеллам. Это подтверждается данными, приведенными в [7], согласно которым коэффициент распределения пирена в мицеллах БЦТА примерно в шесть раз превышает аналопичный показатель для мицелл ДСН.

Квантовый выход фотодепрадации пирена (рис. 9) сильно падает с увеличением концентрации БЦТА и мицеллярного эффекта не наблюдается (хотя солюбилизация в БЦТА протекает значителыно более эффективно, чем в ДСН). Такой характер фотоокисления пирена мож- 


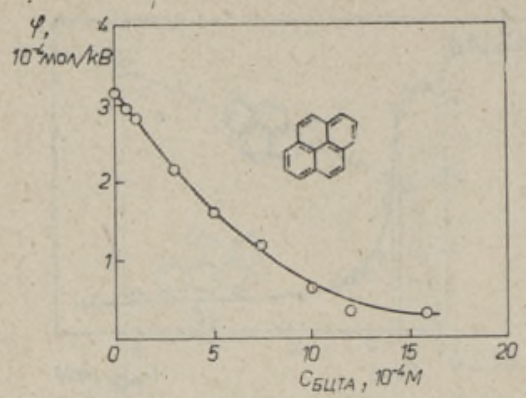

Рис. 9. Зависимость квантового выхода фотоокисления пирена от концентрации БЦТА в водном растворе.

но объяснить тем, что фотолиз ПАУ в водной среде связан в основном с образованием и последующими быстрыми реакциями их катионрадикалов. Причем бромид-ион, входящий в состав использованного ПАВ, способен к эффективному тушению флуоресценции и образующихся катион-радикалов $\left[{ }^{8}\right]$ и, следовательно, определяет падение скорости фотоокисления.

Иной характер имеет ингибирование, обусловленное мицеллообразованием. Резкое падение квантового выхода фотодеградации аренов в мицеллах ДСН, по нашему мнению, обусловлено триплет-триплетной аннигиляцией и концентрационным тушением возбужденных молекул, что приводит к уменышению выхода катион-радикалов. Вероятность такого механизма тушения в мицеллах весьма велика в силу высокой концентрации и ограниченной подвижности в них молекул ПАУ. С другой стороны, к снижению квантового выхода катион-радикалов в мицеллах может привести существенно менышее значение эффективной диэлектрической постоянной микроокружения, которая для мицелл ДСН равна примерно $40\left[^{9}\right]$, что в два раза меныше аналогичной постоянной для воды.

В заключение скажем, что приведенные выше величины коэффициентов распределения значительно меньше уже известных по литературе. Так, по данным [7], коэффициент распределения пирена в мицеллах ДСН составляет $1,17 \cdot 10^{5}$, т. е. в 16 раз выше полученного нами. Известно [10ㄱ, что квантовый выход фотоокисления аренов в органических растворителях зависит от их начальной концентрации. Содержание же ПАУ в мицелле на несколько порядков превышает концентрацию в воде. Поэтому при расчете коэффициентов распределения по формуле (6) необходимо учитывать концентрационный прирост скорости фотоокисления. При этом квантовый выход фотоокисления ПАУ в мицелле следующий:

$$
\varphi_{\mathrm{M}}=\varphi_{\mathrm{M}}^{0}+a A_{\mathrm{M}},
$$

где $A_{\mathrm{M}}$ - концентрация вещества в мицелле; $\varphi_{\mathrm{M}}^{0}-$ квантовый выход фотоокисления при $A_{\mathrm{M}} \rightarrow 0 ; a-$ относительная константа скорости темневых реакций. После подстановки (7) в уравнение (6) с учетом того, что $A_{\mathrm{M}}=\frac{A_{0} P_{A}}{1+P_{A} \cdot C \cdot V}$, получаем следующее выражение

для расчета наблюдаемого экспериментального квантового выхода:

$$
\varphi_{\text {әкс }}=\frac{\left(\varphi_{\mathrm{M}}^{0}+\frac{a \cdot A_{0} \cdot P_{A}}{1+P_{A} \cdot C \cdot V}\right) \cdot C \cdot V \cdot P_{A}+\varphi_{\mathrm{B}}}{1+P_{A} \cdot C \cdot V},
$$

где $A_{0}$ - общая концентрация ПАУ в растворе. Вычисленный на основе уравнения (8) коэффициент распределения пирена между мицеллярной 
фазой ДСН и водой, равный $1,24 \cdot 10^{5}$, хорошо совпадает с данными указанной выше литературы.

Отметим, что искомые параметры в уравнениях (6) и (8) определялись на вычислительном устройстве 15 ВСМ-5 методом оптимизации значений. Расчет коэффициента распределения по формуле (8) для антрацена в ДСН не дал достаточно полного совпадения с величиной из [7] $\left(7,5 \cdot 10^{3}\right.$ против $\left.28,6 \cdot 10^{3}\right)$. В литературе нет аналогичных данных для ДМБА, что лишает нас возможности провести подобное сопоставление.

Примечание. Абсолютные значения квантовых выходов фотодеградации ПАУ, приведенные на рисунках статьи, занижены примерно в 4 раза.

\section{Выводы}

1. Наличие широко иопользуемых $a$-СПАВ в водной среде в концентрациях, не превышающих ККМ, практически мало отражается на величине квантового выхода фотоинициированного окисления изученных аренов (нафталин, антрацен, ДМБА, пирен).

2. Солюбилизация аренов сопровождается резким изменением квантового выхода их фотоокисления. Причем в зависимости от природы $a$-СПАВ наблюдались различные мицеллярные эффекты. Так, в мицеллах ДСН происходит сильное падение скорости фотоокисления ПАУ, а в случае ДБС - небольшой ее рост.

\section{ЛИТЕР А Т Р А}

1. Шам а наев Ш. Ш. Содержание синтетических поверхностно-активных веществ в природных водоемах и нх влняние на флору и фауну водоемов. - В сб.: Гидрохимия Урала, 1975 , № 5 , с. 44-48.

2. Пылев а 3. А., С а ути н А. И. и др. Об активирующем действии сульфанола НП-3 на экспериментальный химический канцерогенез. - В сб.: Гигиенические аспекты охраны окружающей среды, 1976, вып. 4, с. 132-133.

3. Том сон Р. Синтез 1-, 2-, 3-, 4-, 5-, 6-фенилдодеканов. - Изв. АН ЭССР. Физ., Мат., 1966, т. 15 , № 4, c. $447-453$.

4. Mackay, D., Wan Ying Shiu. Aqueous solubility of polynuclear aromatic hydrocarbons. - J. Chem. Eng. Data, 1977, v. 4, p. 399-402.

5. Березин И. В., М а р тинек К., Я цеми иский А. К. Физико-химические основы мицеллярного катализа. - Успехи химии, 1973, вып. 10, с. 1729-1756.

6. Мицеллообразование, солюбилизация и микроэмульсии. М., 1980 , с. 597.

7. Almgren, M., Griesen, F., Thomas, J. K. Dynamic and static aspects of solubilization of neutral arenes in ionic micellar solutions. - J. Amer. Chem. Soc., 1979, v. 101, N 2, p. 279-291.

8. Shizuka, H., Nakamura, M., Morita, T. Anion-induced fluorescence quenching of aromatic molecules. - J. Phys. Chem., 1980, v. 84, N 9, p. $989-994$.

9. Mukerjee, P., Cardinal, J. R. Benzene derivatives and naphthalene solubilized in micelles. Polarity of microenvironment location and distribution in micelles and correlations with surface activity in hydrocarbon-water system. - J. Phys. Chem., 1978, v. 82, N 14, p. 1620-1627.

10. Лопп А., Па альме Л., Губергриц М. Кннетика фотоннициированного окисления 7,12 -диметилбенз(а) антрацена в разных растворителях. - Изв. АН ЭССР. Хим., Геол., 1976, т. 25, № 1, с. 22-27.

Ннститут химии

Академии наук Эстонской ССР
Поступила в редакцию 19/VI 1981 


\section{POLUTSUKLILISTE AROMAATSETE SUSIVESINIKE FOTOKEEMILINE OKSUDATSIOON IOONSETE PINDAKTIIVSETE AINETE MANULUSEL}

Uuritud sünteetiliste pindaktiivsete ainete - naatriumdodetsüülsulfaadi (NDS) ja naatrium-1-detsüülbenseensulfonaadi (DBS) - sisalduse tõstmine lahuses kuni mitsellide moodustumise kriitilise kontsentratsioonini (MKK) mõjutab polütsükliliste areenide (püreen, antratseen, naftaleen, 7,12-dimetüülbenso(a) antratseen) fotooksüdatsiooni kvantsaagiseid ainult vähesel määral. Seevastu üleminekul MKK piirkonda (areeni tunduva lahustumise korral) NDS mitsellides kvantsaagised vähenevad mitmekordselt ning DBS mitsellides mõnevôrra suurenevad.

Polütsükliliste areenide reaktsioonivõime muutus NDS tekitatud mitsellaarses faasis on hästi kirjeldatav Grünwaldi valemiga. Selle abil ongi arvutatud nimetatud areenide jaotuskoefitsiendid vee ja mitsellaarse faasi vahel.

On näidatud, et areenide lahustumisel on peale hüdrofoobse toime oluline tähtsus mitselli polaarsete rühmade ja aromaatse tuuma $\pi$-elektronide süsteemi vastastikusel toimel. NDS mitselli pinnalaengu vähendamisel kasvab oluliselt lahustunud püreeni kogus.

\section{TCHEKULAYEV, I. SHEVCHUK}

\section{THE PHOTOCHEMICAL OXIDATION OF POLYCYCLIC ARENES IN THE PRESENCE OF IONIC SURFACE-ACTIVE AGENTS}

The increase of surface-active agents content - natrium dodecyl sulphate (NDS) and natrium 1-decylbenzene sulphonate (DBS) - in a solution up to the critical concentration of forming micellae (CCM) causes only a negligible decrease of the quantum yield values for the photo-oxidation of polycyclic arenes-(PA) (pyrene, anthracene, naphthalene, 7,12-dimethylbenzo (a) anthracene).

By carrying out the reaction in the CCM-region (under the conditions of a noticeable solubility of arenes), the rate of their photooxidation sharply changes, and namely: in micellaes of NDS, the quantum yields essentially decrease but using DBS they increase to some extent.

The change in the reactivity of PA in the NDS-caused micellar phase can be well described by the Grünwald equation. By using this equation, the distribution coefficients of PA between the micellar phase and water have been calculated. It is shown that besides the hydrophobic properties, the action between the polar groups of the micellae and $\pi$-electron system of aromatic nucleus plays an important role in the solubilization of polycyclic arenes. The degree of the surface charge of NDS micellae causes a remarkable increase in the amount of solubilized pyrene. 